\title{
Employability Skills of College Student in Palangkaraya Central Borneo
}

\author{
Muhammad Noor Fitriyanto $^{1}$, Sugiyanto ${ }^{2}$ \\ Universitas Muhammadiyah Palangkaraya ${ }^{1}$, LPMP Kalimantan Tengah, Palangka Raya ${ }^{2}$ \\ \{riyan.umpalangkaraya@gmail.com ${ }^{1}$, sugiyantolpmpkalteng@gmail.com²\}
}

\begin{abstract}
This study aims to reveal how the level of college students' employability skills and each the level of component's employability skills college student in palangkaraya city. The research was survey research with quantitative approach. It was conducted for college student in Palangka Raya City that is Universitas Muhammadiyah, Institut Agama Islam Negeri Palangaka Raya, and Universitas Palangka Raya. The sampling technique used is multi stage sampling with two stages. First used cluster random sampling and the second determined the sample with proportionate stratified random sampling. The Data were collected using questionnaires technique. The content validity testing used expert judgment and the construct validity testing used confirmatory factor analysis. The reliability testing was carried out using Cronbach Alpha formula. The Data were analyzed using descriptive analysis technique. The results of this study is result employability skills in self management skill 3.31, cooperation or team work skill 3.265, using technology skill 3.252, communication skill 3.200, problem solving skill 3.061, planning and organizing skill 3.004, taking initiative and enterprise skill 3.002, and learning skill 2.967.
\end{abstract}

Keywords: Employability Skills, College Student, Palangkaraya

\section{Introduction}

Human Resources is one that must be considered with the aim of building a community that has good capacity and capability. Another thing is that currently the world is faced with a demographic dividend. Demography is a condition where the number of productive age or young age is more than the elderly. The number of the young population places Indonesia as a contributor to the productive age population as well. This is also based on data from the United Nations (UN) regarding the world's population, that the State of Indonesia in the 20152030 period will get a demographic bonus, which is a bonus for the number of productive ages that is more than the other age population of Indonesia. This age is the age at which the population of a country is mostly in its golden age.

The demographic bonus is an opportunity (window of opportunity) in itself for Indonesia. Based on this, Indonesia can strengthen its economy by optimizing the demographic bonus. The President of the Republic of Indonesia Jokowi also created a special presidential staff by inviting young generations in Indonesia with good talents to join him. This is also reinforced 
by BPS data which shows that population growth can affect economic growth. The participation of the productive age population in economic development is one form of demographic bonus benefits. However, this is not a guarantee for the Indonesian population to get jobs to increase economic growth, but it requires the readiness of the population to work. [4] Wasisto's states that the demographic bonus has not been followed by a strengthening of investment in human resources such as improving education infrastructure has not been given much attention.

In this 21 st century era, countries internationally are faced with the issue of human labor which is replaced by robotic labor. Based on research by [3] Chijindu, robotic workforce is considered to have its own advantages over human labor. Robot workforce has the advantage of not feeling tired so that it can work continuously. Robot workforce also has a high level of precision and robotic workforce is not influenced by mood. Based on this, the government and educational institutions need to find solutions in preparing their graduates to be competitive at that time.

Employability skills are very basic job skills for prospective workers and those who are already employed. Another study conducted by [1] Leroux \& Lafleur escribed that employability skills are important for a person to have. Among the aspects of employability skills, managing yourself is the skill that has the most important level, this is in line with Janice's research that the highest level of employability skills obtained in her research is sequentially starting from self-management, academic skills, and teamwork. Furthermore, a study conducted by [2] Mansour \& Dean lso said that the employability aspects of communication skills and the use of technology are very important for workers to have. Based on these studies, employability skills are an important component for tertiary education graduates to have. In Palangkaraya there are 3 large tertiary institutions whose students are widely used after graduation and are scattered in several areas of the province of Central Kalimantan. Based on the results of the survey, the employability skills of college students in Palangka Raya have not been mapped, so this is an important focus for research. So the research objectives are (1) to reveal the level of students' employability skills (2) to reveal the variations of each type of employability skills of students at the Muhammadiyah University of Palangka Raya, IAIN Palangkaraya, and Palangka Raya University.

\section{Method}

This type of research is a type of survey, namely to describe the attitudes, behavior, opinions, and characteristics of the students' employability skills. Furthermore, the research approach used is a quantitative approach with descriptive analysis, namely an approach where the data from the research results are in the form of described numbers and then presented in the form of graphs, diagrams, tables, pictograms, mean, mode, median standard deviation and variance. This research is limited to describing how high the employability skills of students are by presenting them in the form of diagrams and numbers with descriptions in the form of sentences.

In this study, the instrument used was a questionnaire. The use of a questionnaire is because the measured aspect is an attitude aspect. The study was conducted by analyzing the theories about employability skills, then the results of the study were synthesized into an instrument grid. Furthermore, indicators are developed from the instrument grid. In order to represent the employability skills variable and its sub variables, the indicators developed refer to each sub variable. The next step, each indicator is developed into several statement points. 
Each item represents at least three statements before the instrument validity test is carried out. The data analysis technique used in this research is descriptive statistics. Descriptive statistical methods are statistics used to analyze data by describing or describing research data without intending to make general conclusions or generalizations. In summary, the descriptive statistical method does not test generalizable hypotheses but only to present and analyze data to make it more meaningful. In this employability skills study, researchers will only see how big the levels are through descriptive analysis.

\section{Results and Discussion}

The research results are presented in the form of the calculation results of the central tendency (mean, median, mode), and data distribution. The presentation of the data distribution includes variants and standard deviations. Furthermore, the presentation of the size of the frequency distribution and interpretation of the research data. Interpretation refers to four categories, namely very high, high, medium and low.

\subsection{Employability Skills Level of College Students in Palangka Raya City}

Employability skills are measured using a closed questionnaire with the number of items 42. The answer score per item is 1 to 4 , so that the minimum score obtained is 42 and the maximum score is 168. Based on these data, the ideal average (Mi) is 105 and deviation of criteria (SDi) of 21. Data analysis of students' employability skills using SPSS software, obtained the central tendency and the size of the data distribution, namely a mean of 131.37 , a mode of 127, a median of 130, std. deviation of 10.27, variance of 105.41 , and sum of 29.821 . The minimum value obtained is 104 and the maximum value is 165 . Based on these data, it can be obtained that the value range $(R)=165-104=60$; number of classes $(K)=1+3,3 \log$ $227=8.77$ which is rounded up to 9 ; and the length of the interval $(\mathrm{P})=60: 8.77=6.83$ which is rounded up to 7 . The distribution of variable data scores from the students' employability skills can be seen in the frequency distribution in Table 1.

Table 1. Data Frequency Distribution of Student's Employability Skills

\begin{tabular}{cccccc}
\hline \multicolumn{2}{c}{ Interval } & Frequency & Relative Frequency & Relative Cumulative Frequency \\
\hline 104 & - & 110 & 4 & $1,76 \%$ & $1,76 \%$ \\
111 & - & 117 & 14 & $6,17 \%$ & $7,93 \%$ \\
118 & - & 124 & 32 & $14,1 \%$ & $22,03 \%$ \\
125 & - & 131 & 78 & $34,36 \%$ & $56,39 \%$ \\
132 & - & 138 & 47 & $20,7 \%$ & $77,09 \%$ \\
139 & - & 145 & 30 & $13,22 \%$ & $90,31 \%$ \\
146 & - & 152 & 15 & $6,61 \%$ & $96,92 \%$ \\
153 & - & 159 & 5 & $2,2 \%$ & $99,12 \%$ \\
160 & - & 166 & 2 & $0,88 \%$ & $100 \%$ \\
\hline \multicolumn{2}{c}{ Amount } & $\mathbf{2 2 7}$ & $\mathbf{1 0 0 \%}$ & \\
\hline
\end{tabular}

The frequency distribution of the employability skills variable data can also be displayed in the form of a histogram which can be seen in Figure 1. 


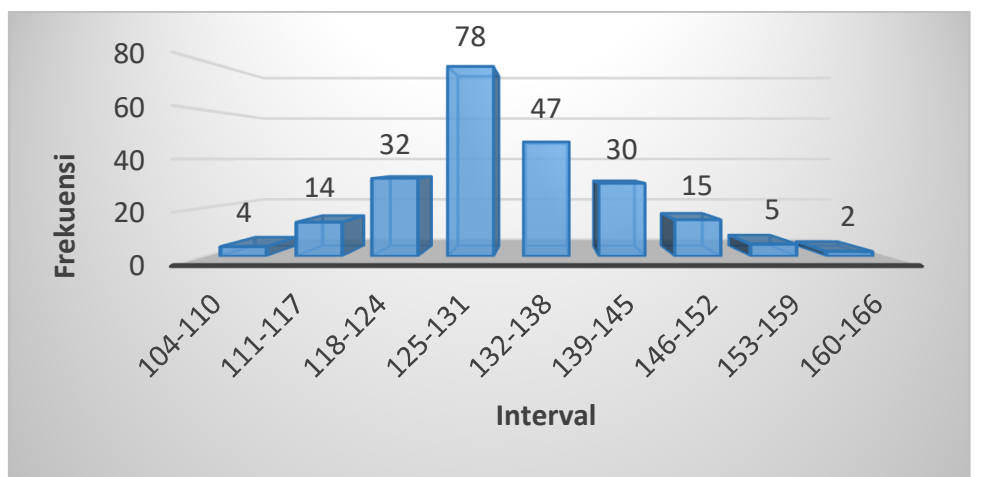

Fig. 1. Data Frequency Distribution Bar Diagram for the Variable Employability Student Skills

Employability skills of students as a whole are in the high category because the average score (131.37) is greater than the ideal average score (105). Furthermore, the trend of each employability skills score is divided into 4 categories with a category range between 42 to 168 which can be seen in detail in Table 2 .

Table 2. Percentage of the Student Aspect Variable Score Trends Employability Skills

\begin{tabular}{|c|c|c|c|c|c|}
\hline \multicolumn{3}{|c|}{ Interval } & Criteria & Frequency & Percentage \\
\hline 136.5 & $<\mathrm{X} \leq$ & 168 & Very High & 63 & $27,8 \%$ \\
\hline 105 & $<X \leq$ & 136.5 & High & 163 & $71,8 \%$ \\
\hline 73,5 & $<\mathrm{X} \leq$ & 105 & Medium & 1 & $0,4 \%$ \\
\hline 42 & $\leq X \leq$ & 73,5 & Low & 0 & $0 \%$ \\
\hline \multicolumn{4}{|c|}{ Amount } & 227 & $100 \%$ \\
\hline
\end{tabular}

Based on Table 2, the percentage of employability skills tendencies in general fall into the medium to very high category. Achieving the score can also be done by comparing the maximum score from the research data (empirical) with the total score determined. Therefore, the employability skills variable of students obtained a total score of 29,821 from the highest score set at 38,136 so that the employability skills variable score obtained a percentage of $78.20 \%$ of the highest score determined based on the very high category. The data description for the employability skills of students in Palangka Raya City consists of eight aspects as follows:

\subsection{Level of Component's Employability Skills College Student in Palangkaraya City}

\section{a) Communication}

Communication as part of the employability skills aspect is measured using a closed questionnaire with a number of items 5 . The answer score per item is 1 to 4 , so that the minimum score obtained is 5 and the maximum score is 20 . Based on these data, the ideal average is obtained (Mi ) is 12.5 and the criteria deviation (SDi) is 2.5. Analysis of student communication data in Palangka Raya City using SPSS software obtained the value of the central tendency and the size of the data distribution, namely the mean of 16 , the mode of 15 , the median of 16 , std. deviation of 1.56 , variance of 2.43 , and sum of 3,632 .

The minimum value of the communication aspect is 12 , then the maximum score is 20 . Overall student communication is in the high category because the average score (16) is 
greater than the ideal average value (12.5). The trend of each score in the communication aspect is divided into four categories ranging from 5 to 20 . The percentage of the tendency of the communication aspect score can be seen in Table 3 .

Table 3. Percentage of Student Communication Aspect Score Tendency

\begin{tabular}{|c|c|c|c|c|c|}
\hline \multicolumn{3}{|c|}{ Interval } & Criteria & Frequency & Percentage \\
\hline 16.25 & $<\mathrm{X} \leq$ & 20 & Very High & 86 & $37,89 \%$ \\
\hline 12.5 & $<X \leq$ & 16.25 & High & 136 & $59,91 \%$ \\
\hline 8.75 & $<X \leq$ & 12.5 & Medium & 5 & $2,2 \%$ \\
\hline 5 & $\leq \mathrm{X} \leq$ & 8.75 & Low & 0 & $0 \%$ \\
\hline \multicolumn{4}{|c|}{ Amount } & 227 & $100 \%$ \\
\hline
\end{tabular}

Based on the percentage category of communication data trends in Table 3, it is known that the level of communication of students generally falls into the medium to very high category. The achievement of the score for the student communication aspect in the city of Palangka Raya obtained a total score of 3,632 from the highest score set at 4,540 so that the score for the communication aspect obtained a percentage of $80 \%$ of the highest score determined based on the very high category.

\section{b) Team Work}

Team Work as part of the employability skills aspect is measured using a closed questionnaire with the number of items 5 . The answer score per item is 1 to 4 , so that the minimum score obtained is 5 and the maximum score is 20 . Based on these data, the ideal average is obtained (Mi ) is 12.5 and the criteria deviation (SDi) is 2.5. Data analysis with students' collaboration using SPSS software obtained the value of the central tendency and the size of the data distribution, namely the mean of 16.33 , the mode of 17 , the median of 16 , std. deviation of 1.66 , variance of 2.76 , and sum of 3.706. The minimum value of the cooperation aspect is 10 , then the maximum value is 20 . Team Work College students in the city of Palangka Raya as a whole are in the high category because the average value (16.33) is greater than the ideal average value (12.5). The tendency of each score on the cooperative aspect is divided into four categories ranging from 5 to 20 . The percentage of the tendency for the team work aspect score can be seen in Table 4.

Table 4. Percentage of Student Team Work Aspect Score Tendency

\begin{tabular}{|c|c|c|c|c|c|}
\hline \multicolumn{3}{|c|}{ Interval } & Criteria & Frequency & Percentage \\
\hline 16.25 & $<\mathrm{X} \leq$ & 20 & Very High & 110 & $48,46 \%$ \\
\hline 12.5 & $<\mathrm{X} \leq$ & 16.25 & High & 114 & $50,22 \%$ \\
\hline 8.75 & $<X \leq$ & 12.5 & Medium & 3 & $1,32 \%$ \\
\hline 5 & $\leq X \leq$ & 8.75 & Low & 0 & $0 \%$ \\
\hline \multicolumn{4}{|c|}{ Amount } & 227 & $100 \%$ \\
\hline
\end{tabular}

Based on the percentage category of the tendency of the data to team work in Table 4, it is known that the level of student collaboration is generally in the medium to very high category. The achievement of the score for the teamwork aspect of college students in the city of Palangka Raya obtained a total score of 3,706 from the highest score set at 4,540 so that the score for the teamwork aspect obtained a percentage of $81.63 \%$ of the highest score determined based on the very high category. 


\section{c) Problem Solving}

Problem solving as part of the employability skills aspect is measured using a closed questionnaire with a number of items 6 . The answer score per item is 1 to 4 , so that the minimum score obtained is 6 and the maximum score is 24. Based on these data, the ideal average is obtained ( Mi) is 15 and the deviation of the criteria (SDi) is 3. Analysis of student problem solving data using SPSS software obtained the value of the central tendency and the size of the data distribution, namely the mean of 18.37 , the mode of 18 , the median of 18 , std. deviation of 1.74 , variance of 3.04 , and sum of 4.169 . The minimum value of the problem solving aspect is 13 , then the maximum score is 24 . The overall student problem solving is in the high category because the average score (18.37) is greater than the ideal average score (15). The tendency of each score on the problem solving aspect is divided into four categories ranging from 6 to 24. The percentage of the tendency for the problem solving aspect score can be seen in Table 5 .

Table 5. The Percentage of the Problem Solving Aspects Score Tendency

\begin{tabular}{cccccc}
\hline & Interval & & Criteria & Frequency & Percentage \\
\hline $\mathbf{1 9 . 5}$ & $<\mathrm{X} \leq$ & 24 & Very High & 46 & $20,26 \%$ \\
$\mathbf{1 5}$ & $<\mathrm{X} \leq$ & 19.5 & High & 172 & $75,77 \%$ \\
$\mathbf{1 0 . 5}$ & $<\mathrm{X} \leq$ & 15 & Medium & 9 & $3,96 \%$ \\
$\mathbf{6}$ & $\leq \mathrm{X} \leq$ & 10,5 & Low & 0 & $0 \%$ \\
\hline \multicolumn{7}{r}{ Amount } & & $\mathbf{2 2 7}$ & $\mathbf{1 0 0 \%}$ \\
\hline
\end{tabular}

Based on the percentage category of problem solving data trends in Table 5, it is known that the level of student problem solving generally falls into the medium to very high category. The achievement of the score for the problem solving aspect of students in Palangka Raya City obtained a total score of 4,169 from the highest score set at 5,448 so that the problem solving aspect score obtained a percentage of $76.52 \%$ of the highest score determined based on the very high category.

\section{d) Take Initiative and Make an Effort}

Taking the initiative and trying as part of the employability skills aspect is measured using a closed questionnaire with the number of items 6 . The answer score per item is 1 to 4 , so that the minimum score obtained is 6 and the maximum score is 24 . Based on these data, the average score is obtained. ideal (Mi) is 15 and the deviation of the criteria (SDi) is 3. Data analysis takes the initiative and attempts of students to use SPSS software, the value of central tendency and the size of data distribution is obtained, namely the mean of 18.01, mode of 18 , median of 18, std . deviation of 1.9, variance of 3.6, and sum of 4.089. The minimum value of the aspect of taking initiative and doing business is 13 , then the maximum value is 24 . Taking initiative and doing business as a whole is in the high category because the average value (18.01) is greater than the ideal average value (15). The tendency of each score on the aspect of taking initiative and trying is divided into four categories ranging from 6 to 24. The percentage of the tendency for the aspect score to take initiative and strive can be seen in Table 6.

Table 6. Percentage of Student Aspect Score Tendency to Take Initiative and Business Interval Criteria Frequency Percentage 


\begin{tabular}{|c|c|c|c|c|c|}
\hline \multicolumn{3}{|c|}{ Interval } & Criteria & Frequency & Percentage \\
\hline 19.5 & $<\mathrm{X} \leq$ & 24 & Very High & 41 & $18,06 \%$ \\
\hline 15 & $<X \leq$ & 19.5 & High & 166 & $73,13 \%$ \\
\hline 10.5 & $<\mathrm{X} \leq$ & 15 & Medium & 20 & $8,81 \%$ \\
\hline 6 & $\leq \mathrm{X} \leq$ & 10,5 & Low & 0 & $0 \%$ \\
\hline \multicolumn{4}{|c|}{ Amount } & 227 & $100 \%$ \\
\hline
\end{tabular}

Based on the percentage category of data tendencies to take initiative and try in Table 6 , it is known that the level of taking initiative and trying for students in general falls into the medium to very high category. The achievement of the aspect score took the initiative and attempted students to obtain a total score of 4,089 from the highest score set at 5,448 so that the aspect score took the initiative and tried to obtain a percentage of $75.05 \%$ of the highest score determined based on the very high category.

\section{e) Planning and Organizing}

Planning and arranging activities as part of the employability skills aspect is measured using a closed questionnaire with the number of items 5 . The answer score per item is 1 to 4 , so that the minimum score obtained is 5 and the maximum score is 20 . Based on these data, the average score is obtained. ideal (Mi) is 12.5 and the criteria deviation (SDi) is 2.5. Data analysis planning and managing student activities using SPSS software obtained the value of the central tendency and the size of the data distribution, namely the mean of 15.02, the mode of 15 , the median of 15 , std. deviation of 1.95 , variance of 3.81 , and sum of 3.409 . The minimum value from the aspect of planning and managing activities is 9 , then the maximum value is 20. Planning and managing student activities in the city of Palangka Raya as a whole is in the high category because the average value (15.02) is greater than the average value. ideal average (12.5). The trend of each score in the aspect of planning and organizing activities is divided into four categories ranging from 5 to 20 . The percentage of the tendency for the score for planning and organizing activities can be seen in Table 7.

Table 7. Percentage of Aspect Score Tendency to Plan and Manage Student Activities

\begin{tabular}{cccccc}
\hline & Interval & & Criteria & Frequency & Percentage \\
\hline $\mathbf{1 6 . 2 5}$ & $<\mathrm{X} \leq$ & 20 & Very High & 47 & $20,7 \%$ \\
$\mathbf{1 2 . 5}$ & $<\mathrm{X} \leq$ & 16.25 & High & 157 & $69,16 \%$ \\
$\mathbf{8 . 7 5}$ & $<\mathrm{X} \leq$ & 12.5 & Medium & 23 & $10,13 \%$ \\
$\mathbf{5}$ & $\leq \mathrm{X} \leq$ & 8.75 & Low & 0 & $0 \%$ \\
\hline \multicolumn{7}{c}{ Amount } & & $\mathbf{2 2 7}$ & $\mathbf{1 0 0 \%}$ \\
\hline
\end{tabular}

Based on the percentage category of the data tendency to plan and organize activities in Table 7, it is known that the level of planning and organizing student activities is generally in the medium to very high category. Achieving the score for planning and managing student activities in Palangka Raya obtained a total score of 3,409 from the highest score set at 4,540 so that the score for the aspect of planning and managing activities obtained a percentage of $75.09 \%$ of the highest score determined based on the very high category. 


\section{f) Self Management}

Self-management as part of the employability skills aspect is measured using a closed questionnaire with a number of items 5 . The answer score per item is 1 to 4 , so that the minimum score obtained is 5 and the maximum score is 20 . Based on these data, the ideal average is obtained ( $\mathrm{Mi}$ ) is 12.5 and the criteria deviation (SDi) is 2.5. The data analysis of student self-management using SPSS software obtained the value of the central tendency and the size of the data distribution, namely the mean of 16.56 , the mode of 17 , the median of 17 , std. deviation of 2.11 , variance of 4.46 , and sum of 3.758 . The minimum value of the selfmanagement aspect is 6 , then the maximum score is 20 . The overall student self-management is in the high category because the average score (16.56) is greater than the ideal average value (12.5). The tendency of each score on the self-management aspect is divided into four categories ranging from 5 to 20 . The percentage of the tendency for the score for the selfmanagement aspect can be seen in Table 8 .

Table 8. Percentage of Student Scores for Student Self-Management

\begin{tabular}{|c|c|c|c|c|c|}
\hline \multicolumn{3}{|c|}{ Interval } & Criteria & Frequency & Percentage \\
\hline 16.25 & $<\mathrm{X} \leq$ & 20 & Very High & 125 & $55,07 \%$ \\
\hline 12.5 & $<\mathrm{X} \leq$ & 16.25 & High & 96 & $42,29 \%$ \\
\hline 8.75 & $<\mathrm{X} \leq$ & 12.5 & Medium & 3 & $1,32 \%$ \\
\hline 5 & $\leq X \leq$ & 8.75 & Low & 3 & $1,32 \%$ \\
\hline \multicolumn{4}{|c|}{ Amount } & 227 & $100 \%$ \\
\hline
\end{tabular}

Based on the percentage category of self-management data in Table 8, it is known that the level of self-management of students is generally in the low to very high category. The achievement of the score for the self-management aspect of students in the city of Palangka Raya obtained a total score of 3,758 from the highest score set at 4,540 so that the score for the self-management aspect obtained a percentage of $82.77 \%$ from the highest score determined based on the very high category.

\section{g) Learning}

Learning as part of the employability skills aspect is measured using a closed questionnaire with the number of items 5 . The answer score per item is 1 to 4 , so that the minimum score obtained is 5 and the maximum score is 20 . Based on these data, the ideal average is obtained (Mi ) is 12.5 and the criteria deviation (SDi) is 2.5. Analysis of student learning data using SPSS software obtained the value of the central tendency and the size of the data distribution, namely a mean of 14.83 , a mode of 15 , a median of 15 , std. deviation of 1.72 , variance of 2.96 , and sum of 3.367 . The minimum value of the learning aspect is 10 , then the maximum value is 20 . Overall student learning is in the high category because the average value (14.83) is greater than the ideal average value (12.5). The trend of each score in the learning aspect is divided into four categories ranging from 5 to 20 . The percentage of the tendency for the learning aspect scores can be seen in Table 9 .

Table 9. Percentage of Student Learning Data Score Trends

\begin{tabular}{|c|c|c|c|c|c|}
\hline & Interval & & Criteria & Frequency & Percentage \\
\hline 16.25 & $<\mathrm{X} \leq$ & 20 & Very High & 40 & $17,62 \%$ \\
\hline 12.5 & $<X \leq$ & 16.25 & High & 167 & $73,57 \%$ \\
\hline 8.75 & $<\mathrm{X} \leq$ & 12.5 & Medium & 20 & $8,81 \%$ \\
\hline
\end{tabular}




\begin{tabular}{|c|c|c|c|c|c|}
\hline \multicolumn{3}{|c|}{ Interval } & Criteria & Frequency & Percentage \\
\hline 5 & $\leq X \leq$ & 8.75 & Low & 0 & $0 \%$ \\
\hline \multicolumn{4}{|c|}{ Amount } & 227 & $100 \%$ \\
\hline
\end{tabular}

Based on the category of the percentage of learning data trends in Table 9, it is known that the level of student learning is generally in the medium to very high category. The achievement of the score for the student learning aspect obtained a total score of 3,367 from the highest score set at 4,540 so that the learning aspect score obtained a percentage of $74.16 \%$ from the highest score determined based on the very high category.

\section{h) Using Technology}

Using technology as part of the employability skills aspect is measured using a closed questionnaire with the number of items 5 . The answer score per item is 1 to 4 , so the minimum score obtained is 5 and the maximum score is 20 . Based on these data, the ideal average is obtained ( Mi) is 12.5 and the criteria deviation (SDi) is 2.5. Data analysis using student technology in the city of Palangka Raya using SPSS software obtained the value of the central tendency and the size of the data distribution, namely the mean of 16.26 , the mode of 15 , the median of 16 , std. deviation of 1.74 , variance of 3.04 , and sum of 3.691 . The minimum value of the aspect of using technology is 13 , then the maximum value is 20 . Using technology, students as a whole are categorized as high because the average value (16.26) is greater than the ideal average value (12.5). The trend of each score on the aspect of using technology is divided into four categories ranging from 5 to 20 . The percentage of the tendency for the aspect of using technology to be seen in Table 10 .

Table 10. Percentage of Trends in Score Data Using Technology

\begin{tabular}{cccccc}
\hline & Interval & & Criteria & Frequency & Percentage \\
\hline $\mathbf{1 6 . 2 5}$ & $<\mathrm{X} \leq$ & 20 & Very High & 93 & $40,97 \%$ \\
$\mathbf{1 2 . 5}$ & $<\mathrm{X} \leq$ & 16.25 & High & 134 & $59,03 \%$ \\
$\mathbf{8 . 7 5}$ & $<\mathrm{X} \leq$ & 12.5 & Medium & 0 & $0 \%$ \\
$\mathbf{5}$ & $\leq \mathrm{X} \leq$ & 8.75 & Low & 0 & $0 \%$ \\
\hline \multicolumn{7}{c}{ Amount } & & $\mathbf{2 2 7}$ & $\mathbf{1 0 0 \%}$ \\
\hline
\end{tabular}

Based on the category of the proportion of data using technology in Table 10, it is known that the level of students' use of technology is generally in the high to very high category. The achievement of the aspect score using student technology in the city of Palangka Raya obtained a total score of 3.691 from the highest achievement set at 4.540 so that the aspect score using technology obtained a proportion of $81.3 \%$ of the score determined based on the very high category.

Based on the presentation of the analysis above, the order of each aspect of the employability skills of students in Palangka Raya City can be grouped by looking at the average score. The group sequence of aspects of the students' employability skills in Palangka Raya City can be seen in Table 11.

Table 11. Comparison of Aspect Levels of College Student Employability Skills in Palangka Raya City

\begin{tabular}{lccc}
\hline \multicolumn{1}{c}{ Skills } & Mean & $\begin{array}{c}\text { Mean divided by } \\
\text { the item statement }\end{array}$ & Rank \\
\hline Self Management & 16.56 & 3,311 & 1 \\
\hline Team Work & 16,33 & 3,265 & 2 \\
\hline
\end{tabular}




\begin{tabular}{lccc}
\hline \multicolumn{1}{c}{ Skills } & Mean & $\begin{array}{c}\text { Mean divided by } \\
\text { the item statement }\end{array}$ & Rank \\
\hline Using Technology & 16,26 & 3,252 & 3 \\
\hline Communication & 16 & 3,2 & 4 \\
\hline Problem Solving & 18,37 & 3,061 & 5 \\
\hline Plan and Organizing & 15,02 & 3,004 & 6 \\
\hline Take Initiative & 18,01 & 3,002 & 7 \\
\hline Learning & 14,83 & 2,967 & 8 \\
\hline
\end{tabular}

Based on the research results, it is known that the level of students' employability skills in Palangkaraya city is generally categorized in high level. The level of students' employability skills, if viewed in more detail based on each component of the employability skills, shows that the level of emplyability skills of students at the Muhammadiyah University of Palangkaraya, IAIN Palangkaraya, and Palangkaraya University is generally in the high category. This category is obtained by comparing the average value of the students' employability skills obtained with the criteria / ideal average score (Mi), where the average value obtained is greater than the ideal average score (105). In this study, it was found that the students 'employability skills were classified as good, so it could be said that the students' employability skills had increased.

\section{Conclusion}

The employability skills of students in Palangka Raya city have been mapped with the following results:

a) In general, the employability skills of college students in Palangkaraya City fall into the high category, namely by comparing the average score of college student 131.37 with the ideal average value (105).

b) The level of aspects of college students' employability skills is generally in the high category. If sorted from the largest average value to the smallest, namely selfmanagement 3.31, cooperation 3.265, using technology 3.252, communication 3.200, problem solving 3.061, planning and organizing activities 3.004, taking initiative and trying 3.002, and learning 2.967 .

\section{References}

[1] Leroux \& Lafleur.: Applications Of Soft Skills In Engineering Programme At Polytechnic Malaysia. Procedia - Social and Behavioral Sciences 140 (2014) 115 120 (2006)

[2] Mansour, Bassou El \& Dean, Jason C.: Employability Skills as Perceived by Employers and University Faculty in the Fields of Human Resource Development (HRD) for Entry Level Graduate Jobs. Journal of Human Resource and Sustainability Studies, (4), 39-49 (2015)

[3] V. C. Chijindu and H. C. Inyiama.: Social inplications of robots - An overview. International Journal of Physical Sciences. Vol. 7, (8), pp. 1270-1275 (2012)

[4] Warsito.: Bonus Demografi Sebagai Mesin Pertumbuhan Ekonomi: Jendela Peluang Atau Jendela Bencana di Indonesia. Jurnal Populasi, Vol. 23 No.1 2015, 1-19 (2015) 